\title{
What do dental schools think of safety syringes?
}

\author{
Use of safety dental syringes in British and Irish dental schools.

\section{J. M. Zakrzewska and E. C. Boon Br Dent J 2003; 195: 207-209}

Aim

The aim of the present study was to determine what types of dental syringes were being used in British dental schools and whether recent studies on the use of safety syringes had had any impact.

\section{Introduction}

In 2001 a controlled trial showed that avoidable needlestick injuries could be reduced with the introduction of safety syringes which did not require the re-sheathing or removal of a needle from its syringe.

Method

A self complete questionnaire asking about safety syringe use was distributed through the deans of all 16 dental schools in the UK and Ireland.

\section{Results}

Fifteen schools formally replied and data are available for the missing one. Two schools have totally converted to the use of safety syringes and in seven schools some departments are using them. Six schools are not considering a change, four others are hoping to change and four are undecided as to whether they are going to change. Five schools had tried them previously. All acknowledge that extensive training is essential, there is also considerable staff resistance and the safety syringes currently available are still not ideal.

\section{Conclusion}

All dental schools should determine their avoidable needlestick injuries rates, reconsider their views on the use of safety syringes and contribute to the development of the ideal model.

\section{IN BRIEF}

- Risk of a needlestick injury is reduced if safety syringes are used.

- UK dental schools are changing over to safety syringes.

- All dental staff should be considering changing to safety syringes.

- Changing over does require investment of time in training.

\section{COMMENT}

Approximately a third of needlestick injuries are potentially avoidable, yet occupational needlestick injuries have persisted despite over two decades of using barrier methods to dispose of needles and increased awareness of the risks from blood borne viruses (BBV). Sharps injuries in general practice range from 1.7-3.5 per annum ${ }^{1,2}$ and are unlikely to fall further without the introduction of safety needles. These are of particular relevance in dental schools where injuries are more common amongst inexperienced junior dental students. ${ }^{4}$ The value of safety needles has been recognised in the US and the Needlestick Safety and Prevention Act was introduced in 2001 to improve staff and patient safety. The legislation requires the use and evaluation of safety-engineered sharps devices in all healthcare facilities.

In the UK, the Department of Health is reviewing changes to the legislation on health clearance checks for BBV in clinical staff joining the NHS, who perform exposure prone procedures. ${ }^{3}$ Therefore a survey in British dental schools by Zakrzewska etal. on the use of safety syringes designed to reduce the risk of needlestick injuries and the acquisition of occupational infection from BBV is timely. The survey showed that only two schools had converted to the use of safety syringes and a further seven schools had adopted safety syringes in some departments. Barriers to change included staff resistance, requirement for extensive training and dissatisfaction with safety syringe performance or design.

Previously, Zakrzewska et a $\left.\right|^{5}$ have shown elimination of needlestick injuries in staff and students who had been trained in the use of safety syringes. However, such positive finding are not universal and studies demonstrating the comparative benefits of different brands of safety syringes are limited, which may explain some of the reluctance to introduce these devices in dental schools. It must be borne in mind that as needlestick injuries are a relatively uncommon event, experiments designed to demonstrate the efficacy of different safety devices based on injury rates would require a sample size of 100,000 to 4.5 million safety syringe injections depending on the expected reduction in needlestick injuries. ${ }^{6}$ The American legislation requiring evaluation of safety needle devices should generate invaluable performance data. In the short-term, selection of devices will be guided by practical considerations such as ease of use, reliability, cost-effectiveness of the device and personal preferences.

C. Pankhurst, King's College London Dental Institute doi:10.1038/sj.bdj.4810442

1. Gore SM, Felix D H, Bird A G, Wray D. Occupational risk and precautions related to HIV infection among dentists in the Lothian region of Scotland. JInfect 1994 : 28: 209-222. Siew C, Gruninger SE, Miaw C L, Neidle E A. Percutaneous injuries in practicing dentists. A prospective study using a 20-day diary. J Am Dent Assoc 1995; 126: 1227-1234.

3. Department of Health. Health clearance for serious communicable diseases: report from the ad hoc risk assessment expert group. Revised edition. London: DoH, 2002. Available at <http://www.doh.gov.uk/healthclear/expertgroup.htm>

4. Younai FS, Murphy D C, Kotelchuck D. Occupational exposures to blood in a dental teaching environment: results of a ten-year surveillance study. J Dent Educ 2001; 65: 436-448.

5. Zakrewska J M, Greenwood I, Jackson J. Introducing safety syringes into a UK dental School- a controlled study. BrDent J2001: 190: 88-92.

6. Pugliese G, Germanson TP, Bartley J, Luca J, Lamerato L, Cox J, Jagger J. Evaluating sharps safety devices meeting OSHA's intent. Infect Control Hosp Epidemiol 2001; 22: 456-458. 